\title{
Effects of barium-ferrite permanent magnets on great hammerhead shark Sphyrna mokarran behavior and implications for future conservation technologies
}

\author{
Craig P. O'Connell ${ }^{1,2, *}$, Saang-Yoon Hyun ${ }^{1}$, Samuel H. Gruber ${ }^{3}$, Pingguo He ${ }^{1}$ \\ ${ }^{1}$ School for Marine Science and Technology, University of Massachusetts Dartmouth, 706 South Rodney French Boulevard, \\ New Bedford, MA 02744, USA \\ ${ }^{2}$ O'Seas Conservation Foundation, Bronx, NY 10463, USA \\ ${ }^{3}$ Bimini Biological Field Station, Bimini, Bahamas
}

\begin{abstract}
The great hammerhead shark Sphyrna mokarran is an endangered species that is exposed to several sources of anthropogenic mortality, including beach nets. Although not a major contributor to $S$. mokarran mortality, beach nets are utilized in several locations to minimize the potential harmful interaction between sharks and beachgoers. To address this mortality, permanent magnets have been employed to determine if these materials can deter sharks away from netted areas. The present study examined the effects of barium-ferrite $\left(\mathrm{BaFe}_{12} \mathrm{O}_{19}\right)$ permanent magnets on S. mokarran behavior under several environmental and biological conditions. In the bait experiment, feeding frequency significantly decreased and avoidance frequency significantly increased with the magnet treatment, with exposure quantity yielding an increase in feeding frequency, although this effect was not statistically significant. For the barrier experiment, entrance frequency significantly decreased and avoidance and pass-around frequencies significantly increased with the magnet treatment, with heterospecific density also being a significant predictor of entrance frequency. The findings demonstrate how permanent magnets can modify S. mokarran behavior and how this behavior is modified based on situational context. Since several other sphyrnid species are caught in beach nets more frequently than $S$. mokarran (e.g. scalloped hammerheads $S$. lewini), the present results may serve as a model for these other sphyrnid species and illustrate the potential conservation implications of future magnetic deterrent barrier technologies.
\end{abstract}

KEY WORDS: Beach nets · Great hammerhead shark · Sphyrna mokarran · Permanent magnets · Elasmobranch mortality

\section{INTRODUCTION}

The great hammerhead shark Sphyrna mokarran is the largest of all sphyrnid species. This species is geographically widespread and has a range that extends throughout coastal and pelagic ecosystems associated with warm temperate to tropical waters

\footnotetext{
*Corresponding author: oseasfdn@gmail.com
}

(Gilbert 1967, Taniuchi 1974, Compagno 1984, Hammerschlag et al. 2011). Within its range, S. mokarran is subjected to several sources of anthropogenic mortality, including targeted capture for shark meat and fins, bycatch and subsequent discard in commercial and recreational fisheries, and beach net entanglement (e.g. Cliff 1995, Abercrombie et al. 2005, Zee- 
berg et al. 2006). This mortality is concerning due to the life history characteristics of $S$. mokarran, such as (1) low fecundity in comparison to other marine organisms, such as teleosts (Stevens \& Lyle 1989), (2) late sexual maturity (Cliff 1995, Last \& Stevens 2009), and (3) slow growth (Piercy et al. 2010). Due to its intrinsically low rebound potential and current population status, S. mokarran is listed as 'Endangered' in the International Union of the Conservation of Nature (IUCN) Red List (Denham et al. 2007). Additionally, it was recently voted to list $S$. mokarran in the CITES (Convention of the International Trade in Species of Wild Flora and Fauna) Appendix II, indicating that strict controls of mortality and trading are required in order to reduce over-exploitation of this species.

Despite these regulations and restrictions, current legal and illegal fishing efforts and the use of beach nets continue to contribute to $S$. mokarran mortality, as well as the mortality of several other sphyrnid species, including scalloped ( $S$. lewini) and smooth (S. zygaena) hammerhead sharks. Beach nets are utilized in several locations around the world to minimize the interaction risk between potentially dangerous sharks and beachgoers (Dudley 1997). With variations in deployment strategies and location-specific environmental conditions, catch statistics pertaining to each region differs. For example, in KwaZulu-Natal, South Africa, a total of 209 S. mokarran and 3385 S. lewini were captured from 1978 to 1993 (Cliff 1995) and 1978 to 1998 (de Bruyn et al. 2005), respectively. In New South Wales, Australia, a total of 1292 Sphyrna spp. were captured from 1990 to 2008; however, because this program typically identified the catch to the genus level, species-specific data is not available (Green et al. 2009). In Queensland, Australia, a total of 148 S. mokarran, 264 S. lewini and 259 unidentified sphyrnid sharks, were captured from 1992 to 2008 (Sumpton et al. 2011). Due to the relatively high capture stress associated with these animals (Morgan \& Burgess 2007), sphyrnid species are not typically released alive, illustrating a need to develop methods to reduce mortality to animals ensnared in shark exclusion devices.

To address the issue of beach net-associated shark mortality, scientists have explored the use of permanent magnets (Rigg et al. 2009, O'Connell et al. 2011a,b, 2014a). Unlike temporary magnets or electromagnets, permanent magnets either inherently create their own persistent magnetic field or retain magnetism upon initial magnetization and do not require an electrical supply. Therefore, permanent magnets exhibit characteristics that make them promising and cost-effective candidates for conservation engineering technologies. Furthermore, these stimuli are hypothesized to target the acute and unique electrosensory system, known as the ampullae of Lorenzini (Kalmijn 1982). This sensory system is composed of minute jelly-filled pores and is most commonly known to be used to detect the minute bioelectric fields (e.g. Kajiura \& Holland 2002) associated with prey and presumably to detect the Earth's magnetic field, which ranges from 0.25 to 0.65 Gauss (G) (Kalmijn 1982, Klimley et al. 2002, Meyer et al. 2005). The mechanism of bioelectric field detection is based around voltage gradients. Each ampullae contains a pore at the skin surface which connects to a subcutaneous canal filled with conductive jelly (Kalmijn 1966, 1971, 1974, 2000, Bastian 1994). Upon encountering a weak electrical stimulus, such as that produced by prey, the voltage external to the pore surface differs from the internal voltage potential. This voltage gradient elicits a neurological impulse, which is sent to the brain where the stimulus is then perceived (Kalmijn 1974, 1982, 1984). In contrast to the presumably well-known mechanisms governing electric field detection, the mechanisms governing magnetic field detection in elasmobranchs are not as well understood, and although magnetic field detection is thought to occur through the ampullary system, this concept remains under scientific debate (e.g. Kalmijn 1982, 1984, Walker et al. 2003). However, the most current explanation as to how elasmobranchs detect magnetic fields is through the process of indirect-based magnetoreception via electromagnetic induction (Kalmijn 1982, 1984). For example, relative to direction, a shark swimming horizontally through the Earth's magnetic field will result in an induced electromotive force according to Faraday's Law. As demonstrated by Johnsen \& Lohmann (2008), an elasmobranch swimming horizontally at $1 \mathrm{~m} \mathrm{~s}^{-1}$ could generate a voltage gradient at the receptor as high as $25 \mu \mathrm{V} \mathrm{m}^{-1}$. Since elasmobranchs have been demonstrated to have a detection threshold that is in the order of nanovolts (e.g. Bastian 1994, Kajiura \& Fitzgerald 2009), the induced voltages associated with the induction-based mechanism exceed this threshold, making this mechanism theoretically plausible.

Using this concept, it is hypothesized that permanent magnets, or materials that produce a magnetic flux that is orders of magnitude greater in strength than geomagnetic fields, would elicit deterrent responses due to the novelty and strength of the stimulus. Studies, such as O'Connell et al. (2011b, 
2014a), demonstrate that small-scale permanent magnetic barriers can manipulate swim patterns of great white sharks Carcharodon carcharias and lemon sharks Negaprion brevirostris. With these findings, the present study aimed to further examine the utility of grade $\mathrm{C} 8$ barium-ferrite $\left(\mathrm{BaFe}_{12} \mathrm{O}_{19}\right)$ permanent magnets and their ability to manipulate $S$. mokarran behavior to provide an understanding of the potential utility of magnetassociated conservation engineering technologies for sphyrnid species. Although other sphyrnid species are entangled in beach nets at higher frequencies (de Bruyn et al. 2005), due to similarities in functional morphology, the findings associated with S. mokarran are suggested to serve as a model for overall sphyrnid species behavior. Therefore, due to the ideal experimental conditions (e.g. shallow and clear water) that allowed for accurate behavioral observations, the utility of permanent magnets as S. mokarran deterrents, or as sphyrnid deterrents, was evaluated by conducting (1) a bait experiment to assess $S$. mokarran sensitivity to permanent magnetic fields and (2) a small-scale barrier experiment to determine the swim pattern manipulation properties of a permanent magnetic barrier on $S$. mokarran. Based on previous experiments (O'Connell et al. 2011b, 2014a), it was hypothesized that magnet-associated baits and barriers would overstimulate the electrosensory system of interacting $S$. mokarran and cause behavioral modification. Besides basic behavioral data, additional data pertaining to biological (i.e. habituation, conspecific and heterospecific density) and environmental (i.e. water visibility) variables were collected to determine the conditions that may yield optimal magnetic repellency. As observed in previous studies, habituation was not observed in sharks repeatedly exposed to permanent magnets (O'Connell et al. 2014a,c), and therefore, it is hypothesized that S. mokarran electromagnetic field habituation will not occur throughout experimentation. Secondly, although $S$. mokarran is considered a solitary shark species, it is hypothesized that because of intraspecific and interspecific competition (Crombie 1947, Polis 1981, Munday et al. 2001), high conspecific and heterospecific densities will reduce deterrent success. Lastly, since the extent of an elasmobranch's visual range is directly related to water visibility properties, it is hypothesized that low visibility conditions that may completely restrict vision may heighten electrosensory system reliance, thus maximizing the effectiveness of magnetic deterrents on S. mokarran.

\section{MATERIALS AND METHODS}

The study was conducted from January 2010 to March 2013 in the shallows of South Bimini, Bahamas. The study site consisted of a sandy substrate that ranged in depth from 3 to $8 \mathrm{~m}$. Over the course of 36 d, 2 different experiments were conducted: (1) the bait experiment and (2) the barrier experiment. To identify individual sharks throughout each experiment, HD GoPro Hero 3 1080p cameras were deployed from the side of the boat. Post-hoc video analysis was then conducted to aid in identifying individual sharks using short-term identification characteristics, including shark size, sex, body color, presence/absence of a tag, presence/absence of fin damage, and presence/absence of scars. All research was conducted in accordance with the rules and regulations of the assigned Bahamas Department of Marine Resources permit (MAF/FIS/17).

\section{Bait experiment}

At the study location, 3 polyvinyl chloride (PVC; $38 \mathrm{~mm}$ diameter) apparatus measuring $1 \mathrm{~m}^{2}$ were deployed: the control (C), a baited apparatus; the procedural control (PC), a baited apparatus containing 1 clay brick $(215 \times 102 \times 67 \mathrm{~mm})$ in the center of the apparatus; and the magnet $(\mathrm{M})$, a baited apparatus containing 1 grade $\mathrm{C} 8$ barium-ferrite $\left(\mathrm{BaFe}_{12} \mathrm{O}_{19}\right)$ permanent magnet $(152 \times 102 \times 51 \mathrm{~mm})$ in the center of the apparatus (Fig. 1). Barium-ferrite permanent magnets generate a flux which decreases at the inverse cube in relation to the distance from the magnet, from near $1000 \mathrm{G}$ at the source to a level comparable to the Earth's magnetic field $(0.25$ to $0.65 \mathrm{G})$ at distances of 0.30 to $0.50 \mathrm{~m}$. These magnets and clay bricks were covered in black duct tape to make these experimental treatments visually identical. Mesh bags were used to affix bait in the center of the apparatus to prevent removal of bait by teleosts. Within each mesh bag, a $0.23 \mathrm{~kg}$ piece of great barracuda Sphyraena barracuda was used as bait to attract Sphyrna mokarran to an apparatus.

Once each apparatus was baited, all treatments were deployed with a randomized order of position to eliminate the possibility of side-preference based behavior. Apparatus were spaced at a minimum distance of $1 \mathrm{~m}$ to ensure that strong magnetic fields (exceeding the ambient magnetic field, 0.25 to 0.65 G) associated with the magnet apparatus did not overlap with the control and procedural control apparatus (Fig. 1). Furthermore, the apparatus were 


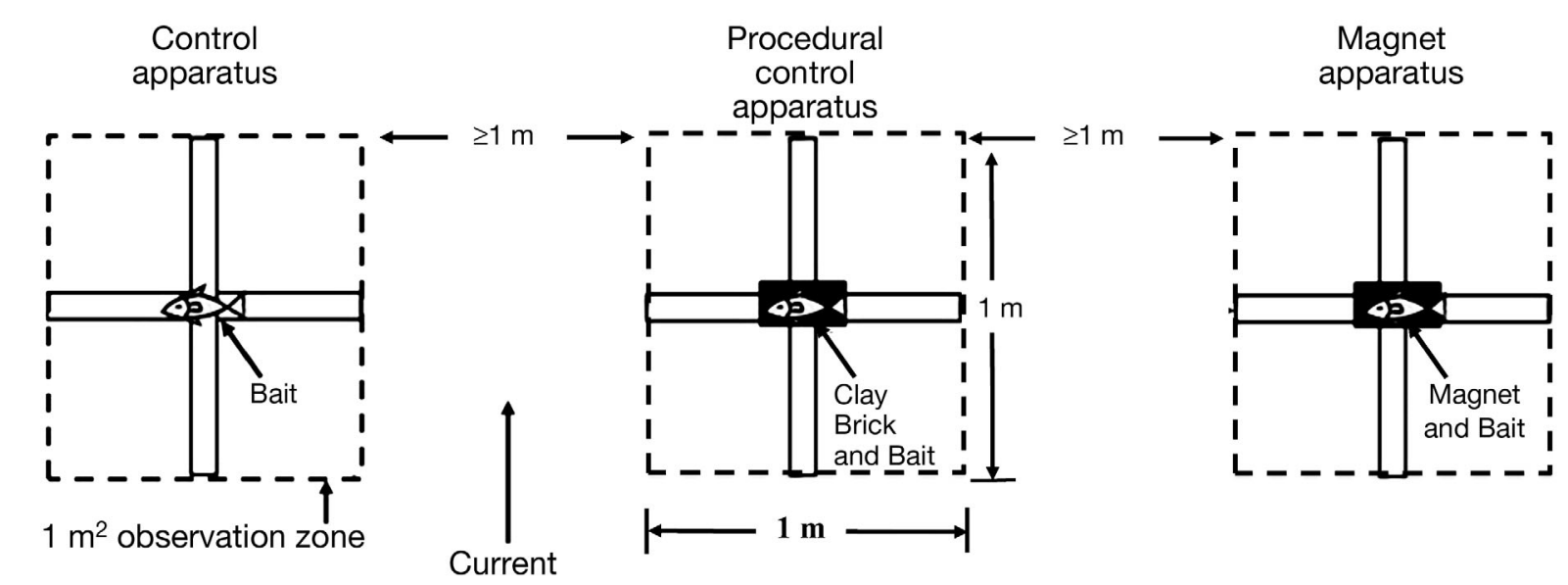

Fig. 1. Bait experiment. See 'Materials and methods' for a detailed description. Dashed lines: observation zone, or region that standardized the location for recordable behaviors

deployed in a line that was perpendicular to the current, so olfactory cues associated with the bait were evenly dispersed to alleviate any potential for treatment-preference behaviors (Fig. 1). Once the apparatus were properly deployed and using a $6.7 \mathrm{~m}$ vessel as an observation platform, the following behaviors were recorded: visits, avoidances, feedings, and no reactions. Visits were recorded when a shark swam within the $1 \mathrm{~m}^{2}$ observation zone (e.g. over the PVC frame). Avoidance behaviors were recorded when a visit followed by a $45^{\circ}, 90^{\circ}, 180^{\circ}$ turn, and/or acceleration away from a treatment zone was observed. Feedings were recorded when a shark was observed to bite or remove bait from an apparatus. Lastly, no reaction was recorded when a shark visited an observation zone, but did not exhibit any of the other previous behaviors. If any bait was removed during a trial, the trial was immediately terminated, each apparatus was rebaited, and a new trial was conducted.

\section{Barrier experiment}

The barrier apparatus consisted of 3 treatment zones: control (C), procedural control (PC), and magnet (M) (Fig. 2). All zones contained a nylon surface rope with 5 yellow polyform buoys $(305 \mathrm{~mm}$ diameter) spaced at $1.50 \mathrm{~m}$ intervals. For the control zone, there was no further experimental manipulation. For the procedural control and magnet zones, 1 vertical column (i.e. $95 \mathrm{~mm}$ diameter flex piping) measuring $3.05 \mathrm{~m}$ in length was suspended below each surface buoy. For the procedural control zone, sham magnets (clay tiles, $\sim 152 \times 102 \times 13 \mathrm{~mm}$ ) were attached at $0.66 \mathrm{~m}$ intervals on each vertical column, with a larger sham magnet (clay brick, 215 $\times 102 \times 67 \mathrm{~mm}$ ) secured to the bottom of the column to ensure the columns were suspended vertically. For the magnet treatment columns, grade C8 barium-ferrite magnets $(152 \times 102 \times 13 \mathrm{~mm})$ were placed at $0.66 \mathrm{~m}$ intervals, with larger grade C8 barium-ferrite magnets $(152 \times 102 \times 52 \mathrm{~mm})$ placed at the bottom of each column. Both magnets and sham magnets were covered in black duct tape to make each experimental treatment visually identical. Five vertical columns per treatment zone were deployed per trial (Fig. 2), with treatment zone being randomized on a per trial basis to reduce the possibility of side-preference based behavior. To permit accurate identification of each treatment region, each region was separated by 1 treatment-separation column (3.05 m length) which was attached to a conspicuous $305 \mathrm{~mm}$ diameter orange surface buoy. Buoy diameter was used as reference for estimating shark distance from the apparatus.

Additionally, 2 equal-sized great barracuda or wahoo Acanthocybium solandri were placed up current of the treatment zones in order to attract elasmobranchs towards the barrier. Using the vessel as an observation platform, 5 main behaviors were recorded: visits, avoidances, entrances, pass arounds, and no reactions. Visits were recorded when a shark swam within an estimated $1 \mathrm{~m}$ of a treatment zone. Avoidance behaviors were recorded when a visit followed by a $45^{\circ}, 90^{\circ}, 180^{\circ}$ turn, and/or acceleration away from a treatment zone was observed. Entrances were recorded when a shark visited an observation zone and swam through the PVC pipes. Pass arounds were recorded when a shark visited 
a)
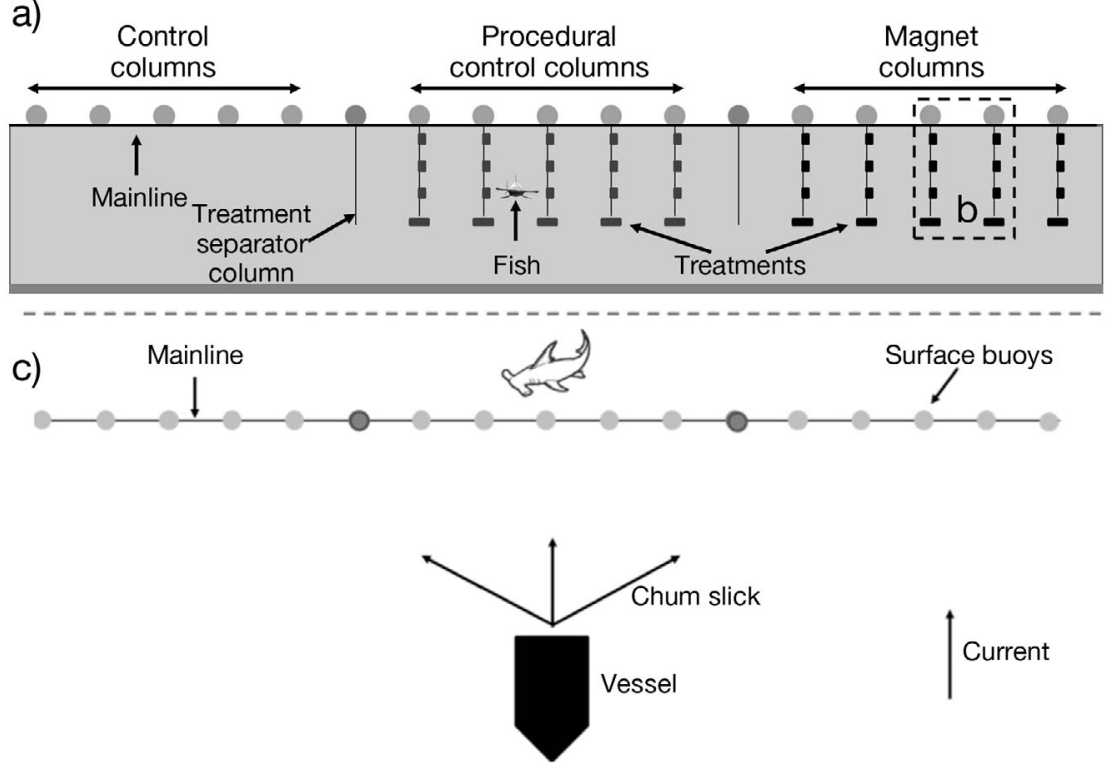

b) I

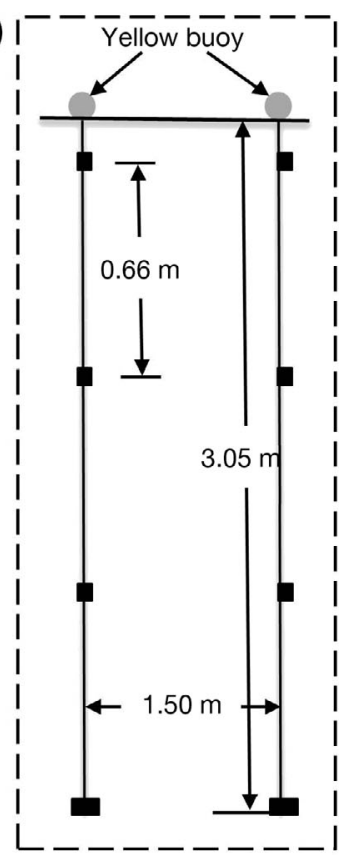

Fig. 2. Barrier apparatus. (a) Side profile of the barrier. Each region of the barrier (control, procedural control, and magnetic) extends a horizontal distance of $6 \mathrm{~m}$. Black squares and rectangles: experimental treatments: clay tiles on the procedural control columns and grade C8 barium-ferrite magnets on the magnet columns. See 'Materials and methods' for a detailed description. (b) Inter-column dimensions. (c) Aerial view of the barrier apparatus, including the upcurrent positioning of the research vessel and chum block

and swam adjacent to an entire observation zone but did not avoid or enter through the zone. Lastly, no reaction was recorded when a shark visited an observation zone, but did not exhibit any of the other previous behaviors.

\section{Additional experimental variables}

During each trial, several candidate explanatory variables were assessed: year (Y), water visibility (V), heterospecific density (HetDe), conspecific density (De), and exposure quantity (Exp), to determine their potential effect on $S$. mokarran behavior towards an experimental treatment. Water visibility was estimated by divers who used inter-vertical column spacing as a reference during the barrier experiment or estimated by using divers as a reference during the bait experiment prior to and after each trial. The calculated mean water visibility from the pre-trial and post-trial observations was used for the overall trial value. Also, for each exposure to the treatments, shark (conspecifics and heterospecifics) abundance within visual range ( 10 to $20 \mathrm{~m}$ from the barrier) was recorded. As individual $S$. mokarran could be accurately identified and re-identified, the number of exposures to a treatment type for each individual could be determined. Exposure quantity for each experimental treatment was either categorized as initial (i.e. first exposure) or secondary (i.e. subsequent exposures). After experimentation, behavioral data were placed within the associated categories for each trial and subjected to statistical analyses.

\section{Statistical analysis}

Data collected throughout experimentation was in the form of frequencies (i.e. counts) for S. mokarran. However, this data was multi-dimensional, where the main effects of several variables and interaction terms between these variables were of interest. Therefore, the traditional chi-square analysis was inefficient in testing hypotheses that involved these multi-dimensions, and instead, we applied a Poisson generalized linear mixed effect model to data for each behavioral category: avoidance, feeding, entrance and pass-around. Analyses pertaining to 'no reaction' were not conducted since the event (i.e. no reaction) is the complement of the other events (i.e. avoidance, feeding, entrance, and pass-around). The multinomial distribution is the joint distribution of 
Poisson distributions, conditional upon their total sum (Dobson \& Barnett 2008). Furthermore, although treatment positioning was randomized throughout experimentation, S. mokarran behaviors were not considered independent since multiple interactions from 1 individual may have occurred with the same treatment regions with time. This may violate the assumption that data are independent, and thus further explains why generalized linear mixed effect models were used. Thus, individual shark was treated as a random effect due to data non-independence, whereas the remaining variables were treated as fixed effects.

The mathematical form of our generalized linear mixed effect model is:

$$
Y=X \beta+\mathrm{S}+\varepsilon
$$

$Y$ represents the column vector of the response variable (counts of shark responses), $X$ is the design matrix of explanatory variables, including all possible interaction terms, $\beta$ is the column vector of coefficients that correspond to explanatory variables, $\mathrm{S}$ is the vector of individual sharks, which is a random effect, and $\varepsilon$ represents the vector of errors, which are assumed to follow a normal (Gaussian) distribution with a mean of zero and constant variance. The fixed effects (i.e. $X$ ) were treatment type (discrete), water visibility (continuous), heterospecific density (continuous), conspecific density (continuous), and exposure quantity (discrete).

The mixed effect model (Eq. 1) was implemented using the 'lme4' package of R (Bates et al. 2012, Hyun et al. 2014, R 3.3.0 Statistical Program). Forward selection was used to determine the best fit model for the data, starting with a null model from which subsequent models were created by adding 1 or several explanatory variables to determine their effect on the response variables (i.e. avoidance frequency, feeding frequency, entrance frequency, and pass-around frequency). We tested the contribution of an explanatory variable, examining the difference in the log-likelihood (Faraway 2006, Hyun et al. 2014):

$$
-2 \times \Delta l \sim \chi^{2}{ }_{\Delta \mathrm{par}}
$$

$\Delta l$ is the difference in the log-likelihood between nested and non-nested models in the forward selection process (see Tables $1 \& 3$ ), and $\Delta$ par is the difference in the number of free parameters between 2 models. Model selection criteria included Akaike's information criteria (AIC), behavior of model residuals using a quantile-quantile (Q-Q) plot, and associated p-values (see Tables 1 \& 3).

\section{RESULTS}

\section{Bait experiment}

A total of 90 trials of $30 \mathrm{~min}$ each were conducted during daylight hours (13:00 to 18:00 h), irrespective of tide, and over the course of $19 \mathrm{~d}$. During each day, an average of 4.74 trials were conducted. Throughout the trials, a minimum of 11 different sharks were identified using short-term identification characteristics. These sharks were present for $52 \%$ (47 trials) of the trials, and the per trial mean visit quantity to the control, procedural control and magnet regions were 3.7, 3.8, and 3.6, respectively (see Table S1 in the Supplement at www.int-res.com/articles/suppl/n026p243_ supp.pdf for overall shark data). Shark length was measured using a baited apparatus as a comparative measure, and ranged from 2 to $4 \mathrm{~m}$. Throughout experimentation, sea surface temperature was $22.8^{\circ} \mathrm{C} \pm$ 1.69 (mean \pm standard deviation), salinity was 36.95 ppt \pm 0.79 , water visibility was $16.82 \mathrm{~m} \pm 5.6$, conspecific density ranged from 1 to 3 , and heterospecific density (adult nurse sharks Ginglymostoma cirratum, which ranged in size from 2 to $3 \mathrm{~m}$ ) ranged from 1 to 8 .

\section{Avoidance}

Data pertaining to avoidance frequency exhibited a clear behavioral distinction between treatment types, with total avoidances equating to control $=0$, procedural control $=1$, and magnet $=21$. However, for secondary validation, a Poisson regression applied to the transformed data (i.e. adding 1 behavioral count to each treatment type) pertaining to the logarithm of avoidance frequency, revealed that the main effect of treatment type (T) was significant. For avoidance frequency, model A2 outperformed all the other models and had the lowest AIC of 74.81 (Table 1) indicating that $\mathrm{T}$ is a significant predictor of avoidance behavior. When referring to model A2, the procedural control $(0.68, t=0.55, \mathrm{p}=0.58)$ and magnet (3.36, $t=0.55, \mathrm{p}=0.001$; Table 2) treatments yielded increases in avoidance frequency; however, only the increase associated with the magnet treatment was statistically significant (Fig. 3a).

\section{Feeding}

When focusing solely on feeding frequency, the main effects of $\mathrm{T}$ and Exp were significant. For feeding frequency, model B10 outperformed all 
Table 1. Model selection process for great hammerhead shark Sphyrna mokarran behavior during the bait experiment. Individual shark (S) is treated as a random effect and the others are treated as fixed effects. These fixed variables are $\mathrm{T}$ (treatment), De (conspecific density), V (water visibility), HetDe (heterospecific density), and Exp (exposure quantity). For avoidance frequency, data were transformed to $\ln$ (total avoidances +1 ) for each treatment region to improve the interpretability of the data, as no avoidances of the control region occurred throughout the entire experiment. Abbreviations: $1=y$-axis intercept, $\Delta l=$ change in log-likelihood value between former model and model being considered, $\Delta$ par = change in degrees of freedom between former model and model being considered, p-value = indicates the level of significance of the explanatory variable added, AIC $=$ Akaike's information criterion $(2 \times(\log$ likelihood) $+2 \times$ number of parameters), a model selection criterion. Selected models for avoidance and feeding frequencies were A2 and B10, respectively, based on a combination of AIC and p-values. Significant models for main effects $(p \leq 0.05)$ and interaction terms $(p \leq 0.1)$ are in bold

\begin{tabular}{|c|c|c|c|c|c|c|}
\hline No. & Model & og-likelihood & $-2(\Delta l)$ & $\Delta$ par & $\mathrm{p}$-value & AIC \\
\hline \multicolumn{7}{|c|}{ Avoidance frequency } \\
\hline A1 & $1+\mathrm{S}$ & -53.57 & - & - & - & 111.13 \\
\hline A2 & $1+\mathrm{S}+\mathrm{T}$ & -33.41 & 140.54 & 2 & $<0.001$ & 74.81 \\
\hline A3 & $1+\mathrm{S}+\mathrm{De}$ & -53.22 & 160.35 & 1 & 0.41 & 112.44 \\
\hline A4 & $1+\mathrm{S}+\mathrm{V}$ & -53.01 & 160.14 & 1 & 0.29 & 112.03 \\
\hline A5 & $1+\mathrm{S}+\mathrm{HetDe}$ & -52.21 & 159.34 & 1 & 0.10 & 110.42 \\
\hline A6 & $1+\mathrm{S}+\operatorname{Exp}$ & -53.53 & 160.66 & 1 & 0.79 & 113.06 \\
\hline A7 & $1+\mathrm{S}+\mathrm{T}+\mathrm{De}$ & -33.30 & 100.12 & 1 & 0.65 & 76.61 \\
\hline A8 & $1+\mathrm{S}+\mathrm{T}+\mathrm{V}$ & -33.29 & 100.11 & 1 & 0.64 & 76.59 \\
\hline A9 & $1+\mathrm{S}+\mathrm{T}+\mathrm{HetDe}$ & -32.95 & 99.76 & 1 & 0.34 & 75.89 \\
\hline A10 & $1+\mathrm{S}+\mathrm{T}+\operatorname{Exp}$ & -33.38 & 100.19 & 1 & 0.81 & 76.76 \\
\hline A11 & $1+\mathrm{S}+\mathrm{T}+\mathrm{De}+\mathrm{T} \times \mathrm{De}$ & -32.57 & 99.18 & 2 & 0.48 & 79.13 \\
\hline $\mathrm{A} 12$ & $1+\mathrm{S}+\mathrm{T}+\mathrm{V}+\mathrm{T} \times \mathrm{V}$ & -33.22 & 99.81 & 2 & 0.92 & 80.44 \\
\hline A13 & $1+\mathrm{S}+\mathrm{T}+\mathrm{HetDe}+\mathrm{T} \times \mathrm{HetDe}$ & -32.39 & 98.28 & 2 & 0.57 & 78.78 \\
\hline A14 & $1+\mathrm{S}+\mathrm{T}+\mathrm{Exp}+\mathrm{T} \times \operatorname{Exp}$ & -31.87 & 98.63 & 2 & 0.22 & 77.74 \\
\hline \multicolumn{7}{|c|}{ Feeding frequency } \\
\hline B1 & $1+\mathrm{S}$ & -67.05 & - & - & - & 138.10 \\
\hline B2 & $1+\mathrm{S}+\mathrm{T}$ & -56.85 & 190.94 & 2 & $<0.001$ & 121.69 \\
\hline B3 & $1+\mathrm{S}+\mathrm{De}$ & -66.62 & 200.71 & 1 & 0.35 & 139.23 \\
\hline B4 & $1+\mathrm{S}+\mathrm{V}$ & -65.59 & 199.68 & 1 & 0.09 & 137.17 \\
\hline B5 & $1+\mathrm{S}+\mathrm{HetDe}$ & -65.69 & 199.79 & 1 & 0.10 & 137.38 \\
\hline B6 & $1+\mathrm{S}+\operatorname{Exp}$ & -65.24 & 199.34 & 1 & 0.06 & 136.48 \\
\hline B7 & $1+\mathrm{S}+\mathrm{T}+\mathrm{De}$ & -56.67 & 170.36 & 1 & 0.56 & 123.35 \\
\hline B8 & $1+\mathrm{S}+\mathrm{T}+\mathrm{V}$ & -56.03 & 169.71 & 1 & 0.20 & 122.05 \\
\hline B9 & $1+\mathrm{S}+\mathrm{T}+\mathrm{HetDe}$ & -56.15 & 169.83 & 1 & 0.24 & 122.29 \\
\hline B10 & $1+\mathrm{S}+\mathrm{T}+\operatorname{Exp}$ & -55.17 & 168.86 & 1 & 0.06 & 120.34 \\
\hline B11 & $1+\mathrm{S}+\mathrm{T}+\mathrm{De}+\mathrm{T} \times \mathrm{De}$ & -56.24 & 169.59 & 2 & 0.65 & 126.48 \\
\hline B12 & $1+\mathrm{S}+\mathrm{T}+\mathrm{V}+\mathrm{T} \times \mathrm{V}$ & -55.27 & 167.32 & 2 & 0.47 & 124.54 \\
\hline B13 & $1+\mathrm{S}+\mathrm{T}+\mathrm{HetDe}+\mathrm{T} \times \mathrm{HetDe}$ & -55.54 & 167.83 & 2 & 0.55 & 125.08 \\
\hline B14 & $1+\mathrm{S}+\mathrm{T}+\operatorname{Exp}+\mathrm{T} \times \operatorname{Exp}$ & -54.33 & 164.67 & 2 & 0.43 & 122.67 \\
\hline
\end{tabular}

other models and contained an AIC of 120.34 (Table 1). The coefficient and associated p-value of the selected model demonstrate that the magnet treatment was significantly negative $(-2.28, t=$ $-3.11, p=0.002$; Table 2), whereas all other components of the model (i.e. procedural control treatment and exposure quantity) were not significant. This finding demonstrates that feeding frequency significantly decreased with the magnet treatment (Fig. 3b).

\section{Barrier experiment}

A total of 42 trials of $30 \mathrm{~min}$ each were conducted during daylight hours (13:00 to $18: 00 \mathrm{~h})$, irrespective of tide, over the course of $2 \mathrm{yr}$ and totaling 17 d. Each day, an average of 2.47 trials were conducted. Additionally, upon initial inspection, year (Y) was found to have no significant influence on response variables. This justified data aggregation over the $2 \mathrm{yr}$ to increase sample size and the subsequent dropping of this variable from model formulation. For both years, a minimum of 14 different sharks were identified using short-term identification characteristics. These sharks were present for $85.6 \%$ (36 trials) of the trials and the per trial mean visit quantity to the control, procedural control and magnet regions were 4.3, 6, and 5.9, respectively (see Table S2 in the Supplement at www.int-res.com/articles/ suppl/n026p243_supp.pdf for overall shark data). Shark length was measured using the barrier as a comparative measure, and ranged from 2 to $3.5 \mathrm{~m}$. Throughout experimentation, sea surface temperature was $23.1^{\circ} \mathrm{C} \pm$ 1.85 (mean $\pm \mathrm{SD})$, salinity was 37.09 ppt \pm 0.65 , water visibility was $16.79 \mathrm{~m}$ \pm 6.08 , conspecific density ranged from 1 to 3, and heterospecific density (adult nurse sharks $G$. cirratum, which ranged in size from 2 to $3 \mathrm{~m}$ ) ranged from 2 to 6 .

\section{Avoidance}

When focusing solely on avoidance frequency, the main effect of treatment type (T) was significant, whereas all other candidate variables were not significant and were thus dropped from the model. For avoidance frequency, model C2 outperformed all other models and had the lowest AIC of 83.38 (Table 3), indicating that treatment type is a significant predictor of avoidance behavior. When referring to model $\mathrm{C} 2$, avoidance frequency was significant and greatest with the magnet treatment $(1.99, t=3.79, \mathrm{p}<0.001$; Table 4; Fig. 4a). 
Table 2. Coefficients, standard errors, $t$-statistic and $\mathrm{p}$-values of explanatory variables for best models A2 and B10 for avoidance and feeding frequencies, respectively, for the great hammerhead shark Sphyrna mokarran during the bait experiment. For avoidance frequency, data were transformed to $\ln$ (total avoidances +1 ) for each treatment region to improve the interpretability of the data, as no avoidances of the control region occurred throughout the entire experiment. Significant models for main effects $(p \leq 0.05)$ and interaction terms $(p \leq 0.1)$ are in bold

\begin{tabular}{|lrrrr|}
\hline $\begin{array}{l}\text { Explanatory } \\
\text { variable }\end{array}$ & Coefficient & $\mathrm{SE}$ & $t$ & $\mathrm{p}$-value \\
\hline $\begin{array}{l}\text { Avoidance frequency } \\
\text { Intercept }\end{array}$ & & & & \\
Magnet & $\mathbf{- 4 . 7 7}$ & $\mathbf{1 . 0 0}$ & $\mathbf{- 4 . 7 7}$ & $<\mathbf{0 . 0 0 1}$ \\
Procedural control & 0.68 & 1.22 & 0.55 & 0.58 \\
Feeding frequency & & & & \\
$\quad$ Intercept & $\mathbf{- 2 . 0 1}$ & $\mathbf{0 . 3 6}$ & $\mathbf{- 5 . 5 2}$ & $<\mathbf{0 . 0 0 1}$ \\
Magnet & $\mathbf{- 2 . 2 8}$ & $\mathbf{0 . 7 3}$ & $\mathbf{- 3 . 1 1}$ & $\mathbf{0 . 0 0 2}$ \\
Procedural control & -0.09 & 0.28 & -0.30 & 0.76 \\
Exposure quantity & 0.63 & 0.37 & 1.71 & 0.09 \\
\hline
\end{tabular}
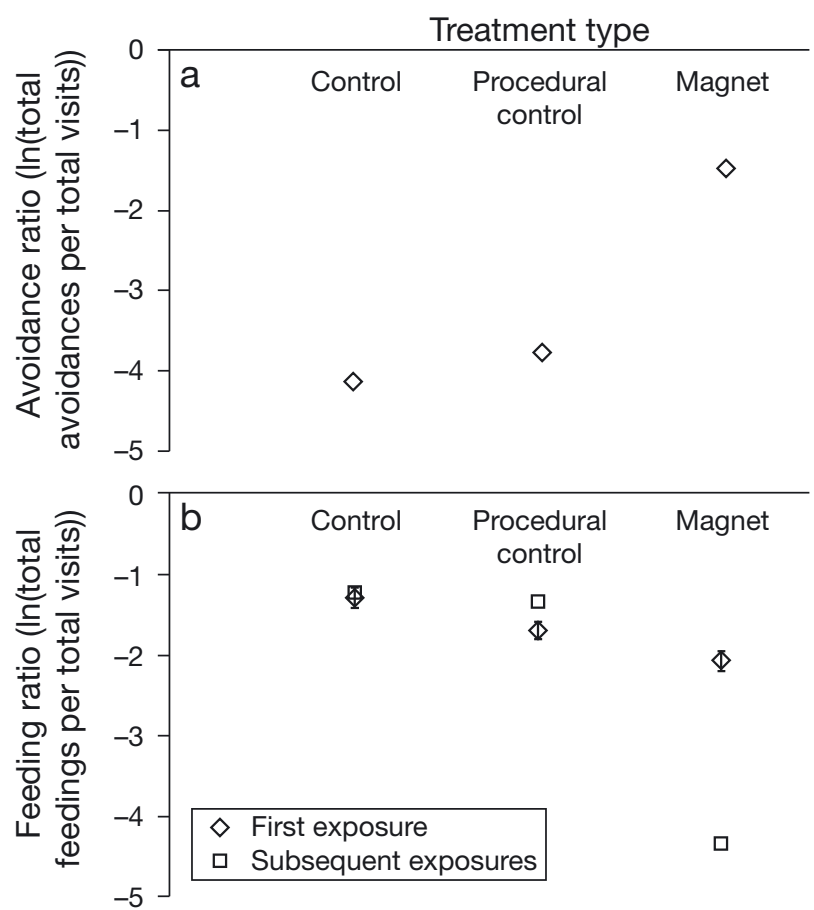

Fig. 3. Best fit models for each great hammerhead shark Sphyrna mokarran behavior (ln(total quantity of behavior/ total visits)) during the bait experiment. (a) Best fit model, A2, pertaining to the outcome variable, the logarithm of avoidances, and the significant predictor variable, treatment type. For avoidance frequency, and since no avoidances of the control treatment were observed, all data were transformed to $\ln$ (total avoidances +1 )/total visits for each treatment type to improve the interpretability of the data. (b) Best fit model, B10, pertaining to the outcome variable, the logarithm of feedings, and the significant predictor variables, treatment type and exposure quantity. Error bars represent the standard error

\section{Entrance}

When focusing solely on entrance frequency, the best fit model included the main effects of $\mathrm{T}$ and HetDe. For entrance frequency, model D9 outperformed all other models and had an AIC of 120.00 (Table 3). When referring to model D9, entrance frequency decreased with the procedural control $(-0.75, t=-3.08, \mathrm{p}=0.002$; Table 4) and magnet $(-1.80, t=-5.02, \mathrm{p}<0.001)$ treatments, with the lowest entrance frequency occurring in the magnet treatment region. Additionally, data also illustrate that with increasing heterospecific density $(0.21, t=$ 2.09, p = 0.04), there was an increased likelihood of entrance through the barrier (Fig. 4b).

In addition to model D9, model D12, which included $\mathrm{T}, \mathrm{V}$, and the interaction between $\mathrm{T}$ and $\mathrm{V}$ $(T \times V)$, was also significant $(p=0.09$; Table 3$)$. However, when the model terms were individually analyzed, only the procedural control treatment and the interaction between the procedural control treatment and water visibility were significant. Data illustrate that the presence of the procedural control treatment significantly reduced entrances through the barrier $(-2.04, t=-2.74, \mathrm{p}=0.01)$. Also, with increasing water visibility conditions, there was an increased likelihood of entrance through the procedural control region of the barrier $(0.08, t=1.99$, $\mathrm{p}=0.05)$.

\section{Pass-around}

When focusing solely on pass-around frequency, the best fit model included the main effect of T). For pass-around frequency, model E2 outperformed all other models and contained the lowest AIC of 114.30 (Table 3) indicating that $\mathrm{T}$ ) was a significant predictor of pass-around behavior, whereas the remaining explanatory variables (i.e. conspecific density, heterospecific density, exposure quantity, and water visibility) were not, and were thus dropped from the model. When referring to model E2, pass-around frequency increased in relation to the magnet $(2.68, t=$ 3.68, p < 0.001; Table 4) and procedural control (2.88, $t=3.98, \mathrm{p}<0.001$; Table 4) treatments, with frequency being relatively even for each of these treatment regions (Fig. 4c).

Besides model E2, model E11 was also significant ( $p=0.05$; Table 3 ) for pass-around behavior and included the main effects of $\mathrm{T}, \mathrm{De}$, and the interaction between these terms $(T \times D e)$. However, all the individual components of the model were not significant. 
Table 3. Model selection process for great hammerhead shark Sphyrna mokarran behavior during the barrier experiment. Individual shark (S) is treated as a random effect and the others are treated as fixed effects. These fixed variables are $\mathrm{T}$ (treatment), De (conspecific density), V (water visibility), HetDe (heterospecific density), and Exp (exposure quantity). Abbreviations: 1 $=y$-axis intercept, $\Delta l=$ change in log-likelihood value between former model and model being considered, $\Delta$ par $=$ change in degrees of freedom between former model and model being considered, $p$-value = indicates the level of significance of the explanatory variable added, AIC $=$ Akaike's information criterion $(2 \times$ (log-likelihood $)+2 \times$ number of parameters $)$, a model selection criterion. Selected models for avoidance, entrance, and pass-around frequencies were C2, D9 and E2, respectively, based on a combination of AIC and $p$-values. Significant models for main effects $(p \leq 0.05)$ and interaction terms $(p \leq 0.1)$ are in bold

\begin{tabular}{|c|c|c|c|c|c|c|}
\hline No. & Model & log-likelihood & $-2(\Delta l)$ & $\Delta$ par & $\mathrm{p}$-value & AIC \\
\hline \multicolumn{7}{|c|}{ Avoidance frequency } \\
\hline $\mathrm{C} 1$ & $1+\mathrm{S}$ & -61.29 & - & - & - & 126.58 \\
\hline $\mathrm{C} 2$ & $1+\mathrm{S}+\mathrm{T}$ & -37.69 & 160.27 & 2 & $<0.001$ & 83.38 \\
\hline C3 & $1+\mathrm{S}+\mathrm{De}$ & -61.19 & 183.77 & 1 & 0.66 & 128.39 \\
\hline $\mathrm{C} 4$ & $1+\mathrm{S}+\mathrm{V}$ & -60.52 & 183.09 & 1 & 0.22 & 127.04 \\
\hline C5 & $1+\mathrm{S}+\mathrm{HetDe}$ & -61.21 & 183.79 & 1 & 0.69 & 128.42 \\
\hline C6 & $1+\mathrm{S}+\operatorname{Exp}$ & -60.45 & 183.03 & 1 & 0.19 & 126.90 \\
\hline $\mathrm{C} 7$ & $1+\mathrm{S}+\mathrm{T}+\mathrm{De}$ & -37.29 & 112.67 & 1 & 0.37 & 84.59 \\
\hline $\mathrm{C} 8$ & $1+\mathrm{S}+\mathrm{T}+\mathrm{V}$ & -37.56 & 112.94 & 1 & 0.61 & 85.12 \\
\hline C9 & $1+\mathrm{S}+\mathrm{T}+\mathrm{HetDe}$ & -37.58 & 112.96 & 1 & 0.64 & 85.16 \\
\hline $\mathrm{C} 10$ & $1+\mathrm{S}+\mathrm{T}+\operatorname{Exp}$ & -36.89 & 112.28 & 1 & 0.21 & 83.79 \\
\hline $\mathrm{C} 11$ & $1+\mathrm{S}+\mathrm{T}+\mathrm{De}+\mathrm{T} \times \mathrm{De}$ & -37.29 & 111.87 & 2 & 0.99 & 88.58 \\
\hline $\mathrm{C} 12$ & $1+\mathrm{S}+\mathrm{T}+\mathrm{V}+\mathrm{T} \times \mathrm{V}$ & -37.39 & 112.51 & 2 & 0.85 & 88.79 \\
\hline $\mathrm{C} 13$ & $1+\mathrm{S}+\mathrm{T}+\mathrm{HetDe}+\mathrm{T} \times \mathrm{HetDe}$ & -36.98 & 112.15 & 2 & 0.55 & 87.97 \\
\hline C14 & $1+\mathrm{S}+\mathrm{T}+\mathrm{Exp}+\mathrm{T} \times \operatorname{Exp}$ & -36.73 & 110.53 & 2 & 0.85 & 87.47 \\
\hline \multicolumn{7}{|c|}{ Entrance frequency } \\
\hline D1 & $1+\mathrm{S}$ & -72.43 & - & - & - & 148.86 \\
\hline D2 & $1+\mathrm{S}+\mathrm{T}$ & -57.02 & 201.89 & 2 & $<0.001$ & 122.05 \\
\hline D3 & $1+\mathrm{S}+\mathrm{De}$ & -72.02 & 216.88 & 1 & 0.36 & 150.03 \\
\hline D4 & $1+\mathrm{S}+\mathrm{V}$ & -71.95 & 216.81 & 1 & 0.33 & 149.90 \\
\hline D5 & $1+\mathrm{S}+\mathrm{HetDe}$ & -71.79 & 216.65 & 1 & 0.26 & 149.58 \\
\hline D6 & $1+\mathrm{S}+\operatorname{Exp}$ & -72.37 & 217.23 & 1 & 0.72 & 150.74 \\
\hline D7 & $1+\mathrm{S}+\mathrm{T}+\mathrm{De}$ & -56.58 & 170.63 & 1 & 0.35 & 123.16 \\
\hline D8 & $1+\mathrm{S}+\mathrm{T}+\mathrm{V}$ & -56.33 & 170.38 & 1 & 0.24 & 122.66 \\
\hline D9 & 1+S+T+HetDe & -55.00 & 169.05 & 1 & 0.04 & 120.00 \\
\hline D10 & $1+\mathrm{S}+\mathrm{T}+\operatorname{Exp}$ & -57.01 & 171.06 & 1 & 0.86 & 124.02 \\
\hline D11 & $1+\mathrm{S}+\mathrm{T}+\mathrm{De}+\mathrm{T} \times \mathrm{De}$ & -55.54 & 168.69 & 2 & 0.35 & 125.08 \\
\hline D12 & $1+\mathrm{S}+\mathrm{T}+\mathrm{V}+\mathrm{T} \times \mathrm{V}$ & -53.94 & 166.59 & 2 & 0.09 & 121.89 \\
\hline D13 & $1+\mathrm{S}+\mathrm{T}+\mathrm{HetDe}+\mathrm{T} \times \mathrm{HetDe}$ & -54.95 & 164.96 & 2 & 0.95 & 123.91 \\
\hline D14 & $1+\mathrm{S}+\mathrm{T}+\mathrm{Exp}+\mathrm{T} \times \operatorname{Exp}$ & -56.39 & 170.42 & 2 & 0.54 & 126.80 \\
\hline \multicolumn{7}{|c|}{ Pass-around frequency } \\
\hline E1 & $1+\mathrm{S}$ & -73.67 & - & - & - & 151.35 \\
\hline E2 & $1+\mathrm{S}+\mathrm{T}$ & -53.15 & 200.50 & 2 & $<0.001$ & 114.30 \\
\hline E3 & $1+\mathrm{S}+\mathrm{De}$ & -73.62 & 220.97 & 1 & 0.74 & 153.24 \\
\hline E4 & $1+\mathrm{S}+\mathrm{V}$ & -73.09 & 220.44 & 1 & 0.28 & 152.18 \\
\hline E5 & $1+\mathrm{S}+\mathrm{HetDe}$ & -73.61 & 220.96 & 1 & 0.71 & 153.22 \\
\hline E6 & $1+\mathrm{S}+\operatorname{Exp}$ & -73.62 & 220.97 & 1 & 0.74 & 153.24 \\
\hline E7 & $1+\mathrm{S}+\mathrm{T}+\mathrm{De}$ & -53.11 & 159.41 & 1 & 0.78 & 116.22 \\
\hline E8 & $1+\mathrm{S}+\mathrm{T}+\mathrm{V}$ & -52.13 & 158.44 & 1 & 0.15 & 114.27 \\
\hline E9 & $1+\mathrm{S}+\mathrm{T}+\mathrm{HetDe}$ & -52.87 & 159.17 & 1 & 0.45 & 115.73 \\
\hline E10 & $1+\mathrm{S}+\mathrm{T}+\mathrm{Exp}$ & -53.05 & 159.35 & 1 & 0.65 & 116.09 \\
\hline E11 & $1+\mathrm{S}+\mathrm{T}+\mathrm{De}+\mathrm{T} \times \mathrm{De}$ & -50.19 & 156.42 & 2 & 0.05 & 114.39 \\
\hline E12 & $1+\mathrm{S}+\mathrm{T}+\mathrm{V}+\mathrm{T} \times \mathrm{V}$ & -51.88 & 156.15 & 2 & 0.78 & 117.76 \\
\hline E13 & $1+\mathrm{S}+\mathrm{T}+\mathrm{HetDe}+\mathrm{T} \times \mathrm{HetDe}$ & -52.47 & 158.20 & 2 & 0.67 & 118.94 \\
\hline E14 & $1+\mathrm{S}+\mathrm{T}+\mathrm{Exp}+\mathrm{T} \times \operatorname{Exp}$ & -52.93 & 159.02 & 2 & 0.89 & 119.85 \\
\hline
\end{tabular}

\section{DISCUSSION}

This study illustrates that both the procedural control and permanent magnet regions can influence the feeding and swimming behavior of Sphyrna mokarran. More specifically, the results illustrate that the best fit models for each response variable changed based on situational context, with the main effect of $\mathrm{T}$ being a significant predictor of avoidance frequency for both experiments, and pass-around frequency for the barrier experiment. The main effects of $\mathrm{T}$ and Exp were significant predictors of feeding frequency, whereas the main effects of $\mathrm{T}$ and HetDe were significant predictors of entrance frequency.

\section{Basic behavioral observations}

S. mokarran behavior was significantly altered in the presence of magnetically treated baits and barriers, which supports the findings from 2 previous studies pertaining to scalloped hammerhead $S$. lewini behavior towards electrosensory stimuli (Rigg et al. 2009, Hutchinson et al. 2012). This magnet-associated behavioral modification may be explained by several hammerhead characteristics, such as the broadened cephalofoil, location of peak pore density, feeding ecology, and visual capabilities. The greater lateral search area associated with the broadened cephalofoil (Kajiura \& Holland 2002) may increase the probability that $S$. mokarran will come within range of and detect the magnets, and therefore could explain this behavioral change in relation to the electromagnetic fields (Figs. 3 \& 4). Additionally, the combination of maximum pore density occurring on the ventral surface of hammerhead cephalofoils (Kajiura 2001, Kajiura et al. 2003) and the feeding ecology of $S$. mokarran, with diets mainly consisting of benthic organisms (Stevens \& Lyle 1989, Cliff 1995), suggests this species may be heavily reliant on its electrosen- 
Table 4. Coefficients, standard errors, $t$-statistic and p-values of explanatory variables for best models C2, D9, and E2 for avoidance, entrance, and pass-around frequencies, respectively, for the great hammerhead shark Sphyrna mokarran during the barrier experiment. Significant models for main effects $(p \leq 0.05)$ and interaction terms $(p \leq 0.1)$ are in bold

\begin{tabular}{|lrrrr|}
\hline $\begin{array}{l}\text { Explanatory } \\
\text { variable }\end{array}$ & Coefficient & $\mathrm{SE}$ & $t$ & $\mathrm{p}$-value \\
\hline Avoidance frequency & & & & \\
\hline $\begin{array}{l}\text { Intercept } \\
\text { Magnet }\end{array}$ & $\mathbf{- 2 . 9 3}$ & $\mathbf{0 . 5 0}$ & $\mathbf{- 5 . 8 6}$ & $<\mathbf{0 . 0 0 1}$ \\
Procedural control & $\mathbf{1 . 9 9}$ & $\mathbf{0 . 5 3}$ & $\mathbf{3 . 7 9}$ & $<\mathbf{0 . 0 0 1}$ \\
Entrance frequency & & 0.87 & -1.09 & 0.28 \\
Intercept & $\mathbf{- 1 . 4 9}$ & $\mathbf{0 . 4 9}$ & $\mathbf{- 3 . 0 7}$ & $\mathbf{0 . 0 0 2}$ \\
Magnet & $\mathbf{- 1 . 8 0}$ & $\mathbf{0 . 3 6}$ & $\mathbf{- 5 . 0 2}$ & $<\mathbf{0 . 0 0 1}$ \\
Procedural control & $\mathbf{- 0 . 7 5}$ & $\mathbf{0 . 2 4}$ & $\mathbf{- 3 . 0 8}$ & $\mathbf{0 . 0 0 2}$ \\
Heterospecific density & $\mathbf{0 . 2 1}$ & $\mathbf{0 . 1 0}$ & $\mathbf{2 . 0 9}$ & $\mathbf{0 . 0 4}$ \\
Pass-around frequency & & & & \\
Intercept & $\mathbf{- 3 . 6 4}$ & $\mathbf{0 . 7 1}$ & $\mathbf{- 5 . 1 3}$ & $<\mathbf{0 . 0 0 1}$ \\
Magnet & $\mathbf{2 . 6 8}$ & $\mathbf{0 . 7 3}$ & $\mathbf{3 . 6 8}$ & $<\mathbf{0 . 0 0 1}$ \\
Procedural control & $\mathbf{2 . 8 8}$ & $\mathbf{0 . 7 2}$ & $\mathbf{3 . 9 8}$ & $<\mathbf{0 . 0 0 1}$ \\
\hline
\end{tabular}

sory system, and thus increasingly susceptible and sensitive to strong permanent magnets.

In addition to the magnet treatment, the barrier's procedural control region had a similar effect on $S$. mokarran swimming behavior. More specifically, entrance frequencies were reduced and pass-around frequencies increased with respect to the procedural control region. With maximized binocular vision and depth perception due to the hammerhead's broadshaped cephalofoil (McComb et al. 2009), it is possible that the associated visual stimuli of the procedural control and magnet regions were sufficient to elicit these behavioral responses. However, although the procedural control columns did impact the entrance and pass-around frequencies of $S$. mokarran, the results pertaining to avoidance and entrance frequencies (Fig. 4b,c) illustrate the heightened effect of magnetism, and thus the sole effect of visual stimuli is not sufficient to explain the findings. Therefore, the potential utilization of permanent magnets for large-scale shark deterrent barrier applications warrants further investigation.

\section{Year}

Temporal variation is a common influencing factor in scientific research, as the properties of biological systems vary with time. Both the bait and barrier experiments were conducted over the course of $2 \mathrm{yr}$ to increase sample size and, therefore, it was important to determine if the results were independent of

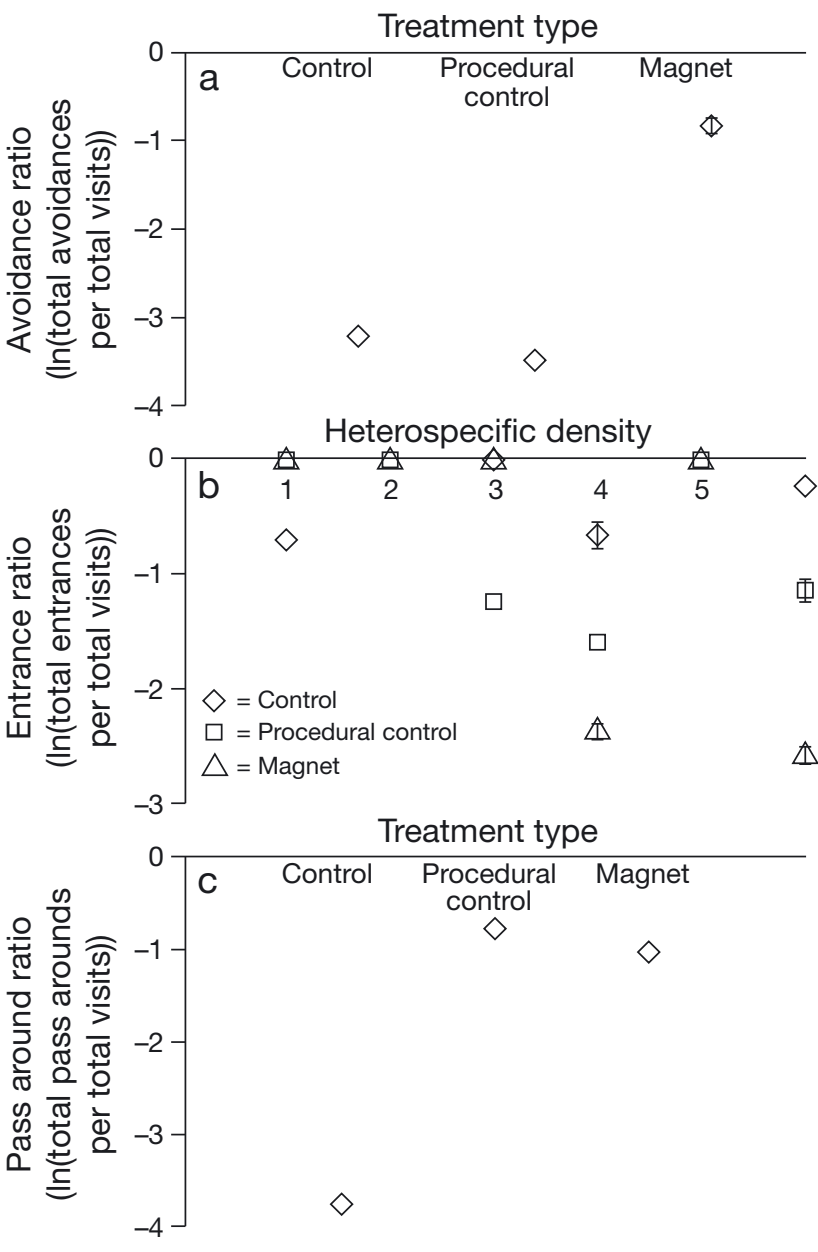

Fig. 4. Best fit models for each great hammerhead shark Sphyrna mokarran behavior (ln(total quantity of behavior/ total visits)) during the barrier experiment. (a) Best fit model, $\mathrm{C} 2$, pertaining to the outcome variable, the logarithm of avoidances, and the significant predictor variable, treatment type. (b) Best fit model, D9, pertaining to the outcome variable, the logarithm of entrances, and the significant predictor variables, treatment type and heterospecific density. (c) Best fit model, E2, pertaining to the outcome variable, the logarithm of pass arounds and the significant predictor variable, treatment type. Error bars represent the standard error

time to assess if data should be annually segregated or aggregated. Based on the results, year was not a significant predictor of any response variable, illustrating that behavior was consistent across years, allowing data to be aggregated during the analysis.

\section{Water visibility}

Throughout the experimentation, water visibility changed; however, the effects of this change did not have any statistically significant influence on the 
response variables with respect to magnetic treatments. These findings are consistent with the null hypothesis, but vary with the findings from a semicaptive behavioral study (O'Connell et al. 2014b). The semi-captive study demonstrated that vision loss, simulating a highly turbid environment, impacted juvenile lemon shark Negaprion brevirostris behavior towards a magnetic barrier ( $\mathrm{O}^{\prime}$ Connell et al. 2014). N. brevirostris behavioral variation was assessed using 4 behavioral benchmarks: (1) visit quantity prior to first entrance, (2) entrance frequency, (3) avoidance distance, and (4) avoidance frequency, with benchmarks 1 to 3 being significant $\left(\mathrm{O}^{\prime}\right.$ Connell et al. 2014). Although the range of visibility (i.e. no visual ability to full visual ability) in the semi-captive study (C. P. O'Connell et al. unpubl.) was drastically different from the conditions in the present study (i.e. minimum water visibility of $10 \mathrm{~m}$ ), it may be premature to suggest that $S$. mokarran behavior towards permanent magnets does not change with varying water visibility, since not all behavioral benchmarks were assessed in the present study, and water visibility conditions simulating blindness were not encountered. Additionally, decreasing water visibility throughout the present experiment may have been a result of light intensity characteristics (i.e. time of day), rather than turbidity, which can severely restrict vision and often yield context-dependent switching in sensory modalities (Leahy et al. 2011, Ranåker et al. 2012). For example, crucian carp Carassius carassius behavior significantly changed with respect to turbidity, becoming more reliant on predator-associated chemical cues to compensate for a lack of visual information (Ranåker et al. 2012). Similarly, Leahy et al. (2011) demonstrated that spiny damselfish Acanthochromis polyacanthus anti-predator behavior significantly increased (i.e. reduced foraging with increasing turbidity). Therefore, future experiments should record both turbidity and water visibility, as the tapetum lucidum (Best \& Nicol 1967, Braekevelt 1994), or intra-ocular reflecting structure, gives these sharks an enhanced ability to see in low-light conditions (Arnott et al. 1970, Ollivier et al. 2004), and thus turbidity levels may be a more important component of water visibility when assessing behavioral changes.

\section{Conspecific and heterospecific density}

Organisms that occupy a similar ecological niche and spatial resource often compete both within (i.e. intraspecific competition) and between (i.e. interspe- cific competition) species (Nelson \& Johnson 1980, Schoener 1983). These interactions have been demonstrated to alter behavior by inducing a competitive mentality (Crombie 1947, Nelson \& Johnson 1980, Polis 1981, Stiling et al. 1984, Munday et al. 2001). In the present study, the main effects of heterospecific density had a positive relationship with entrance frequency, which may be a result of intraspecific competition. However, although olfactory and gustatory cues were used in the bait and barrier experiments, no other significant effects of conspecific and heterospecific densities on response variables were observed. These findings are inconsistent with the present hypotheses and previous studies pertaining to electrosensory success in relation to varying conspecific densities of sandbar sharks Carcharhinus plumbeus (Brill et al. 2009) and Galapagos sharks C. galapagensis (Robbins et al. 2011), and smooth dogfish Mustelus canis (Jordan et al. 2011). Brill et al. (2009) examined the feeding response of $C$. plumbeus at 2 different density levels $(\mathrm{n}=7 ; \mathrm{n}=14)$ to an electropositive metal (EPM) alloy. During highdensity trials, the deterrent effects were minimal and short-lived; however, C. plumbeus demonstrated a sensitivity to EPM alloys during low-density trials. Similarly, Robbins et al. (2011) demonstrated that EPM alloys were ineffective at reducing the depredation rate of $C$. galapagensis at high density levels, whereas in low-density trials, behavior was exploratory and cautious. Jordan et al. (2011) demonstrated that groups of M. canis exposed to EPM-treated baits showed no indications of repellency, whereas individually tested $M$. canis were significantly deterred by EPM-treated baits. Such inconsistencies between the present study and previous studies (Brill et al. 2009, Jordan et al. 2011, Robbins et al. 2011) may be an artifact of varying feeding ecologies between species and therefore illustrates how deterrent effectiveness may be a species-specific phenomenon (i.e. species involved and/or species quantity).

\section{Habituation}

For feeding frequency, the best fit model included the main effects of treatment type and exposure quantity. Although the main effect of exposure quantity was insignificant, the increasing feeding frequency with exposure quantity (Fig. 3b) suggests that preliminary signs of sensory habituation may have been present during this experiment. These findings are consistent with a previous study demonstrating that semi-captive juvenile lemon sharks $N$. 
brevirostris rapidly habituate after being repeatedly exposed to a magnetic stimulus over a duration of $1 \mathrm{~h}$ (O'Connell et al. 2011b). However, exposure quantity for both the bait and barrier experiments was not significant and since $S$. mokarran often had an infrequent exposure rate to each experimental region (e.g. $\sim 1$ to 2 exposures per trial) in comparison to the previous study (O'Connell et al. 2011b; $\sim 60$ exposures per trial), the findings suggest that the differences in exposure rate might have been insufficient to cause significant evidence of sensory habituation. Furthermore, although insignificant, indications of habituation may have been observed in the bait experiment (i.e. feeding frequencies) but not in the barrier experiment because the barrier-associated magnetic stimuli constantly rotated and changed orientation with current and wave energy. This movement may have exposed sharks to varying magnetic field strengths, thus prolonging and/or alleviating short-term habituation. Similar to and in support of this concept, previous shark-related studies have demonstrated how continual low-frequency acoustic stimuli lead to rapid sensory habituation, but variations in the acoustic pulse and/or frequency prolong habituation (Myrberg et al. 1969, 1978). In order to accurately assess habituation, the long-term deployment of these barriers is essential to maximize individual exposure to magnetic fields. If significant indications of habituation are observed in wild shark species, it may reveal a major technological limitation.

\section{Magnetic barriers as shark deterrents}

Findings from this study along with those from previous barrier experiments (e.g. O'Connell et al. $2014 \mathrm{a}, \mathrm{c})$ illustrate that magnets have the ability to manipulate the swim patterns of multiple shark species, including white sharks Carcharodon carcharias and bull sharks Carcharhinus leucas. However, it is essential to recognize the limitation of magnets and how this limitation may influence future implementation of barrier-associated conservation engineering technologies. For example, field observations illustrate that a benthic array of magnets would be an insufficient alternative to beach nets. As observed in the present bait study and in previous experiments (O'Connell et al. 2014a,c), sharks may swim out of range of the magnetic fields by simply swimming over the array. Therefore, positioning the magnets throughout the water column might be a practical approach that would not only target mid-water/ pelagic shark species, but also benthic-oriented elasmobranchs.

Recent studies illustrate that species-specific responses to magnetic barriers do occur (O'Connell et al. 2014a,c). These responses might be associated with a substantial quantity of additional variables, such as feeding ecology (Rigg et al. 2009, Kajiura et al. 2010), habitat utilization (Rigg et al. 2009, Hutchinson et al. 2012), animal size (Sisneros et al. 1998, Sisneros \& Tricas 2002), and animal density (Brill et al. 2009, Jordan et al. 2011, Robbins et al. 2011, see Jordan et al. 2013). Therefore, future research should consider these variables due to their importance for the progression of this research field and the knowledge of magnetic barrier efficacy.

\section{CONCLUSION}

Although effective at reducing shark-human interactions, beach nets continue to impact local and migratory shark populations, in addition to marine organisms that pose little threat to beachgoers. Sphyrna mokarran and closely related species from the family Sphyrnidae are frequently entangled in beach nets, and the results obtained from this study may serve as a model for how other Sphyrna spp. may behave towards magnetic barriers. To determine if magnetic barriers provide a promising alternative to beach nets, future experimentation examining the exclusion properties of this technology should be continued with emphasis on how biological and environmental variables may influence shark behavior towards the magnetic stimuli. Such findings may greatly benefit the understanding pertaining to the conditions that yield maximum deterrent efficacy and, as a result, the locations (i.e. inshore turbid regions vs. offshore non-turbid regions) that may be more appropriate for such technologies.

Acknowledgements. We thank the Bimini Sands Resort and Marina (G. Johnson and K. Grudecki) and the Bimini Biological Field Station (staff and volunteers) for permitting us to use their facilities and/or resources to make this project possible. We thank the University of Massachusetts Dartmouth, the WAVE Foundation and the PADI Foundation for providing funding to make this project possible. Lastly, we thank the Bahamas Department of Natural Resources for granting us permission to conduct this research.

\section{LITERATURE CITED}

Abercrombie DL, Clarke SC, Shivji MS (2005) Global-scale genetic identification of hammerhead sharks: Applica- 
tion to assessment of the international fin trade and law enforcement. Conserv Genet 6:775-788

Arnott HJ, Maciolek NJ, Nicol JAC (1970) Retinal tapetum lucidum: a novel reflecting system in the eye of teleosts. Science 169:478-480

Bastian J (1994) Electrosensory organisms. Phys Today 47: 30-37

Bates D, Maechler M, Bolker B (2012) lme4: Linear mixedeffects models using $\mathrm{S} 4$ classes. $\mathrm{R}$ package version 0.999999-0. http://CRAN.R-project.org/package=lme4

Best ACG, Nicol JAC (1967) Reflecting cells of the elasmobranch tapetum lucidum. Contrib Mar Sci 12:172-201

> Braekevelt CR (1994) Fine structure of choroidal tapetum lucidum in the Port Jackson shark (Heterodontus phillipi). Anat Embryol (Berl) 190:591-596

Brill R, Bushnell P, Smith L, Speaks C, Sundaram R, Stroud E, Wang J (2009) The repulsive and feeding deterrent effects of electropositive metals on juvenile sandbar sharks (Carcharhinus plumbeus). Fish Bull 107:298-307

> Cliff G (1995) Sharks caught in the protective gill nets off KwaZulu-Natal, South Africa. 8. The great hammerhead shark Sphyrna mokarran (Rüppell). S Afr J Mar Sci 15: 105-114

Compagno LJV (1984) FAO species catalogue, Vol. 4. Sharks of the world. An annotated and illustrated catalogue of shark species known to date. Part 2: Carcharhiniformes. FAO Fish Synop 125:251-655 FAO, Rome

Crombie AC (1947) Interspecific competition. J Anim Ecol 16:44-73

de Bruyn P, Dudley SFJ, Cliff G, Smale MJ (2005) Sharks caught in the protective gill nets off KwaZulu-Natal, South Africa. 11. The scalloped hammerhead shark Sphyrna lewini (Griffith and Smith). Afr J Mar Sci 27: 517-528

Denham J, Stevens J, Simpfendorfer CA, Heupel MR and others (2007) Sphyrna mokarran. IUCN Red List of Threatened Species. Version 2012.2. www.iucnredlist.org

Dobson AJ, Barnett AG (2008) An introduction to generalized linear models, 3rd edn. Chapman \& Hall/CRC, Boca Raton, FL

$>$ Dudley SFJ (1997) A comparison of the shark control programs of New South Wales and Queensland (Australia) and KwaZulu-Natal (South Africa). Ocean Coast Manage 34:1-27

Faraway JJ (2006) Extending the linear model with R: Generalized linear, mixed effects and nonparametric regression models. Chapman \& Hall/CRC, Boca Raton, FL

Gilbert CR (1967) A revision of the hammerhead sharks (family Sphyrnidae). Proc US Natl Mus 119(3539):1-88

Green M, Ganassin C, Reid DD (2009) Report into the NSW shark meshing (bather protection) program. NSW Department of Primary Industries, Orange

- Hammerschlag N, Gallagher AJ, Lazarre DM, Slonim C (2011) Range extension of the Endangered great hammerhead shark Sphyrna mokarran in the Northwest Atlantic: preliminary data and significance for conservation. Endang Species Res 13:111-116

Hutchinson M, Wang JH, Swimmer Y, Holland K and others (2012) The effects of a lanthanide metal alloy on shark catch rates. Fish Res 131-133:45-51

Hyun SY, Cadrin SX, Roman S (2014) Fixed and mixed effect models for fishery data on depth distribution of Georges Bank yellowtail flounder. Fish Res 157:180-186

Johnsen S, Lohmann KJ (2008) Magnetoreception in ani- mals. Phys Today 61:29-35

> Jordan LJ, Mandelman JW, Kajiura SM (2011) Behavioral responses to weak electric fields and a lanthanide metal in two shark species. J Exp Mar Biol Ecol 409:345-350

> Jordan LK, Mandelman JW, McComb DM, Fordham SV, Carlson JK, Werner TB (2013) Linking sensory biology and fisheries bycatch reduction in elasmobranch fishes: a review with new directions for research. Conserv Physiol 1:cot002

Kajiura SM (2001) Head morphology and electrosensory pore distribution of carcharhinid and sphyrnid sharks. Environ Biol Fishes 61:125-133

Kajiura SM, Fitzgerald TP (2009) Response of juvenile scalloped hammerhead sharks to electric stimuli. Zoology 112:241-250

Kajiura SM, Holland KN (2002) Electroreception in juvenile scalloped hammerhead and sandbar sharks. J Exp Biol 205:3609-3621

Kajiura SM, Forni J, Summers A (2003) Manuevering in juvenile carcharhinid and sphyrnid sharks: the role of the hammerhead shark cephalofoil. Zoology 106:19-28

Kajiura SM, Cornett A, Yopak K (2010) Sensory adaptations to the environment: electroreceptors as a case study. In: Carrier J, Heithaus M, Musick J (eds) Sharks and their relatives: physiological adaptations, behavior, ecology, conservation, and management. CRC Press, London, p 393-433

> Kalmijn AJ (1966) Electro-perception in sharks and rays. Nature 212:1232-1233

Kalmijn AJ (1971) The electric sense of sharks and rays. J Exp Biol 55:371-383

Kalmijn AJ (1974) The detection of electric fields from inanimate and animate sources other than electric organs. In: Fessard A (ed) Electroreceptors and other specialized receptors in lower vertebrates. Handbook of sensory physiology, Vol 3. Springer-Verlag, Berlin, p 147-200

Kalmijn AJ (1982) Electric and magnetic field detection in elasmobranch fishes. Science 218:916-918

Kalmijn AJ (1984) Theory of electromagnetic orientation: a further analysis. In: Keynes RD, Maddrell SHP (eds) Comparative physiology of sensory systems. Cambridge University Press, Cambridge, p 525-560

Kalmijn AJ (2000) Detection and processing of electromagnetic and near-field acoustic signals in elasmobranch fishes. Philos Trans R Soc Lond B 355:1135-1141

Klimley AP, Beavers SC, Curtis TH, Jorgensen SJ (2002) Movements and swimming behavior of three species of sharks in La Jolla Canyon, California. Environ Biol Fishes 63:117-135

Last PR, Stevens JD (2009) Sharks and rays of Australia, 2nd edn. CSIRO Publishing, Collingwood

Leahy SM, McCormick MI, Mitchell MD, Ferrari MC (2011) To fear or to feed: the effects of turbidity on perception of risk by a marine fish. Biol Lett 7:811-813

> McComb DM, Tricas TC, Kajiura SM (2009) Enhanced visual fields in hammerhead sharks. J Exp Biol 212: 4010-4018

> Meyer CG, Holland KN, Papastamatiou YP (2005) Sharks can detect changes in the geomagnetic field. J R Soc Interface 2:129-130

Morgan A, Burgess GH (2007) At-vessel fishing mortality for six species of sharks caught in the northwest Atlantic and Gulf of Mexico. Gulf Caribb Res 19:1-7

Munday PL, Jones GP, Caley MJ (2001) Interspecific competition and coexistence in a guild of coral-dwelling fishes. 
Ecology 82:2177-2189

Myrberg AA, Banner A, Richard JD (1969) Shark attraction using a video-acoustic system. Mar Biol 2:264-276

Myrberg AA, Gordon CR, Klimley AP (1978) Rapid withdrawal from a sound source by open-ocean sharks. J Acoust Soc Am 64:1289-1297

Nelson DR, Johnson RH (1980) Behavior of the reef sharks of Rangiroa, French Polynesia. Natl Geogr Soc Res Rep 12: 479-498

O'Connell CP, Abel DC, Stroud EM (2011a) Analysis of permanent magnets as elasmobranch bycatch reduction devices in hook-and-line and longline trials. Fish Bull 109:394-401

O'Connell CP, Gruber SH, Abel DC, Stroud EM, Rice PH (2011b) The responses of juvenile lemon sharks, Negaprion brevirostris, to a magnetic barrier. Ocean Coast Manage 54:225-230

O'Connell CP, Andreotti S, Rutzen M, Meyer M, He P (2014a) The use of permanent magnets to reduce elasmobranch encounter with a simulated beach net. 2. The great white shark (Carcharodon carcharias). Ocean Coast Manage 97:20-28

> O'Connell CP, Guttridge TL, Brooks J, Finger JS, Gruber $\mathrm{SH}, \mathrm{He} \mathrm{P}$ (2014b) Behavioral modification of visually deprived lemon sharks (Negaprion brevirostris) towards magnetic fields. J Exp Mar Biol Ecol 453:131-137

O'Connell CP, Hyun SY, Gruber SH, O'Connell TJ, Johnson G, Grudecki K, He P (2014c) The use of permanent magnets to reduce elasmobranch encounter with a simulated beach net. 1. The bull shark (Carcharhinus leucas). Ocean Coast Manage 97:12-19

Ollivier FJ, Samuelson DA, Brooks DE, Lewis PA, Kallberg MA, Komáromy AM (2004) Comparative morphology of the tapetum lucidum (among selected species). Vet Ophthalmol 7:11-22

Piercy AN, Carlson JK, Passerotti MS (2010) Age and growth of the great hammerhead shark, Sphyrna mokarran, in the north-western Atlantic Ocean and Gulf of Mexico. Mar Freshw Res 61:992-998

Polis GA (1981) The evolution and dynamics of intraspecific predation. Annu Rev Ecol Syst 12:225-251

Editorial responsibility: Rory Wilson,

Swansea, UK
Ranåker L, Nilsson PA, Brönmark C (2012) Effects of degraded optical conditions on behavioural responses to alarm cues in a freshwater fish. PLoS ONE 7:e38411.

Rigg DP, Peverell SC, Hearndon M, Seymour JE (2009) Do elasmobranch reactions to magnetic fields in water show promise for bycatch mitigation? Mar Freshw Res 60: 942-948

Robbins WD, Peddemors VM, Kennelly SJ (2011) Assessment of permanent magnets and electropositive metals to reduce the line-based capture of Galapagos sharks, Carcharhinus galapagensis. Fish Res 109:100-106

> Schoener TW (1983) Field experiments on interspecific competition. Am Nat 122:240-285

Sisneros JA, Tricas TC (2002) Ontogenetic changes in the response properties of the peripheral electrosensory system in the Atlantic stingray (Dasyatis sabina). Brain Behav Evol 59:130-140

Sisneros JA, Tricas TC, Luer CA (1998) Response properties and biological function of the skate electrosensory system during ontogeny. J Comp Physiol A 183:87-99

Stevens JD, Lyle JM (1989) Biology of three hammerhead sharks (Eusphyra blochii, Sphyrna mokarran, S. lewini) from northern Australia. Aust J Mar Freshw Res 40: 129-146

Stiling PD, Brodbeck BV, Strong DR (1984) Intraspecific competition in Hydrellia valida (Diptera: Ephydridae), a leaf miner of Spartina alterniflora. Ecology 65:660-662

Sumpton WD, Taylor SM, Gribble NA, McPherson G, Ham T (2011) Gear selectivity of large-mesh nets and drumlines used to catch sharks in the Queensland Shark Control Program. Afr J Mar Sci 33:37-43

Taniuchi T (1974) Three species of hammerhead sharks in the southwestern waters of Japan. Jpn J Ichthyol 21: $145-152$

Walker MM, Diebel CE, Kirschvink JL (2003) Detection and use of the Earth's magnetic field by aquatic vertebrates. In: Collin SP, Marshall NJ (eds) Sensory processing in aquatic environments. Springer, New York, NY, p 53-74

Zeeberg J, Corten A, de Graaf E (2006) Bycatch and release of pelagic megafauna in industrial trawler fisheries off Northwest Africa. Fish Res 78:186-195

Submitted: January 6, 2014; Accepted: June 23, 2014 Proofs received from author(s): November 13, 2014 